\title{
Commercially available granulates PMMA and PS - potential problems with the production of polymer optical fibers
}

\author{
Mateusz Jóźwicki ${ }^{1}$, Mateusz Gargol ${ }^{1}$, Małgorzata Gil-Kowalczyk ${ }^{* 2}$, Paweł Mergo $^{2}$ \\ ${ }^{1}$ Department of Polymer Chemistry, Maria Curie-Skłodowska University, Maria Curie-Skłodowska Sq. 5, \\ 20-031, Lublin, Poland \\ ${ }^{2}$ Laboratory of Optical Fibers Technology, Maria Curie-Sklodowska University, Maria Curie-Sklodowska Sq. 5, \\ 20-031, Lublin, Poland
}

Received July 07, 2020; accepted September 23, 2020; published September 30, 2020

\begin{abstract}
The aim of the study was to verify the usefulness of commercially available granulates of PMMA (poly (methyl methacrylate) and PS (polystyrene) to produce polymer optical fibers by extrusion method. Samples were subjected to thermal processing in various conditions (different temperatures and exposure time). Thermal (TG/DTG) and spectroscopic (ATR/FT-IR) analyses were carried out to analyze changes in the samples. Based on FT-IR analysis of liquid monomers and granulates, the conversion of double bonds was calculated, which gave us a picture of the degree of monomers conversion - the crucial information from a technological point of view.
\end{abstract}

PMMA and PS are one of the most popular materials used to produce polymer optical fibers (POF). They have their advantages and disadvantages compared to traditional silica optical fibres. The advantages are low weight, resistance to electromagnetic interference and multiplexing possibilities. In addition, they are a cheaper alternative to traditional silica fibres and can be bent more because of their greater plasticity. The disadvantage is higher transmission losses. The above features have made POF attractive for telecommunications applications such as short distance data transfer, e.g. local or home internet connections, automotive applications and as sensors [1-3]. There are different methods of producing POF. For the general use, where high purity is not required, a granulate extrusion method is used. The advantages of this method are, among others, the lack of synthesis stage and material cleaning or the use of special substances like chain transfer agent or thermal initiator [4]. Production methods are important because they affect all the properties of POF, in particular, attenuation. It is therefore very important to optimise the fibre extrusion process and to optimise the synthesis and purification of the ingredients [5]. Therefore, one of the main objectives of the work was to examine the effect of temperature on the chemical structure of PMMA and PS granules from which POF will be made.

All equipment used for this study were presented previously [6].

\footnotetext{
*E-mail: malgorzata.gil@ poczta.umcs.lublin.pl
}

Spectroscopic analyses of ATR-FT-IR and double bond conversion were carried out according to the article [6]. The conclusions from the mentioned work is that based on spectroscopic studies, the highest extrusion temperature of PMMA-POF is $240^{\circ} \mathrm{C}$. According to double bond conversion calculations the optimal extrusion temperature is $210^{\circ} \mathrm{C}$.

The ATR-FTIR spectroscopic analysis of the PS granulate (Synthos, Lobeček, Czech Republic) was carried out analogously to the analysis of PMMA granulate, the difference being that they were carried out only at $180^{\circ} \mathrm{C}$, $210^{\circ} \mathrm{C}$ and $240^{\circ} \mathrm{C}$ after $20,40,60 \mathrm{~min}$ and the temperature $270^{\circ} \mathrm{C}$ was not used because already at $240^{\circ} \mathrm{C}$ the PS started to flow and became a bit yellow (indicating thermal decomposition). The spectra were normalized to the $755 \mathrm{~cm}^{-1}$ reference band, as a result of non-plane deformation $=\mathrm{C}-\mathrm{H}$ in the aromatic ring. This band does not change as the temperature increases, as shown in Fig. 1 and Tab. 1.

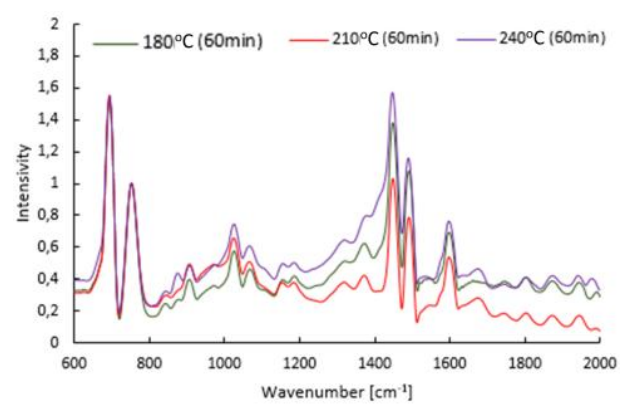

Fig. 1. PS in $180^{\circ} \mathrm{C}, 210^{\circ} \mathrm{C}, 240^{\circ} \mathrm{C}$ ATR-FT-IR full spectra range

Table 1 shows the differences in the intensity of the band $1075 \mathrm{~cm}^{-1}$ arising from plate deformation $=\mathrm{C}-\mathrm{H}$ in the aromatic ring and $1645 \mathrm{~cm}^{-1}$ stretching aromatic $-\mathrm{C}=\mathrm{C}-$. 
Table 1 . PS band intensity measured in temperature $180^{\circ} \mathrm{C}, 210^{\circ} \mathrm{C}$, and $240^{\circ} \mathrm{C}$.

\begin{tabular}{|c|c|c|c|}
\cline { 2 - 4 } \multicolumn{1}{c|}{} & \multicolumn{3}{c|}{ Band intensity } \\
\cline { 2 - 4 } \multicolumn{1}{c|}{} & $755 \mathrm{~cm}^{-1}$ & $1075 \mathrm{~cm}^{-1}$ & $1645 \mathrm{~cm}^{-1}$ \\
\hline \multicolumn{4}{|c|}{$90^{\circ} \mathrm{C}$} \\
\hline $120 \mathrm{~min}$ & 1.0 & 0.5 & 0.5 \\
\hline \multicolumn{3}{|c|}{$180^{\circ} \mathrm{C}$} & 0.5 \\
\hline $20 \mathrm{~min}$ & 1.0 & 0.5 & 0.5 \\
\hline $40 \mathrm{~min}$ & 1.0 & 0.5 & 0.4 \\
\hline $60 \mathrm{~min}$ & 1.0 & 0.5 & 0.3 \\
\hline \multicolumn{4}{|c|}{$210^{\circ} \mathrm{C}$} \\
\hline $20 \mathrm{~min}$ & 1.0 & 0.4 & 0.3 \\
\hline $40 \mathrm{~min}$ & 1.0 & 0.4 & 0.3 \\
\hline $60 \mathrm{~min}$ & 1.0 & 0.5 & 0.3 \\
\hline \multicolumn{3}{|l|}{$240^{\circ} \mathrm{C}$} \\
\hline $20 \mathrm{~min}$ & 1.0 & 0.6 & 0.2 \\
\hline $40 \mathrm{~min}$ & 1.0 & 0.5 & 0.4 \\
\hline $60 \mathrm{~min}$ & 1.0 & 0.6 & \\
\hline
\end{tabular}

Based on the above data, it appears that the chemical structure of PS is stable at the tested temperatures, 180$240^{\circ} \mathrm{C}$ because only slight differences in band intensity are visible. It should be noted that for the sample heated in $240^{\circ} \mathrm{C}$ some changes for band corresponding to stretching aromatic are observed. Also, at this temperature samples started to flow, which can indicate loosening of the structure and that is why possible changes in the structure are observed.

Double bond conversion was calculated according to the formula presented previously [6] and the results are shown in Tab. 2.

Table 2. Double bond conversion PS.

\begin{tabular}{|c|c|c|c|}
\hline \multirow{2}{*}{ Temperature $\left[{ }^{\circ} \mathrm{C}\right]$} & \multicolumn{3}{|c|}{ Time $[\mathrm{min}]$} \\
\cline { 2 - 4 } & 20 & 40 & 60 \\
\hline 90 & \multicolumn{3}{|c|}{73.1} \\
\hline 180 & 82.3 & 87.7 & 88.2 \\
\hline 210 & 90.5 & 91.3 & 93.5 \\
\hline 240 & 95.3 & 95.8 & 92.2 \\
\hline
\end{tabular}

From the data collected in Table 2 it is clear that the conversion of double bonds increases significantly with the temperature increase. Similarly, conversions of double bonds are affected by the heating time. The above table shows that both at $180^{\circ} \mathrm{C}$ and $210^{\circ} \mathrm{C}$ with the time increase, the double bond conversion increases. That means that the granulates are not properly polymerized. Therefore, the tested material should be polymerized first, and then subjected to time and temperature tests. Regarding the temperature of $240^{\circ} \mathrm{C}$, apart from the fact that at this temperature the substance is so fluid that it is not suitable for extrusion, the conversion of double bonds reaches a high value of $95 \%$, at $20 \mathrm{~min}$. At the same time, it can be seen that by increasing the process time the conversion decreases. This means that there are changes in the polymer structure that were not noticed during the study of PS-specific bands intensity.

To test the thermal stability of obtainable POF from commercial granulates, TG/DTG analyses were carried out. The curves received from TG and DTG analyses for all samples are presented in Figures 2 and 3, while Table 3 gives the main parameters assessed on their basis: initial decomposition temperature (IDT) for $1 \%$ mass loss of the sample, maximum decomposition temperature (Max DTG) and maximum decomposition rate (DTG) (TG curves present only the beginning of mass loss, since only the initial temperatures are significant in the optical fiber production process).
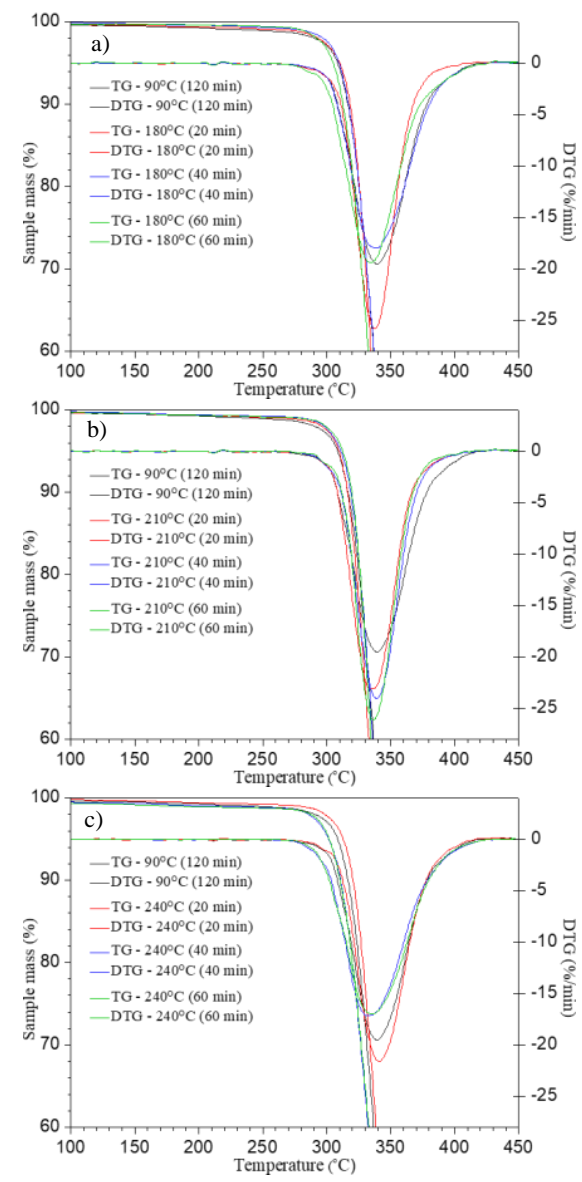

Fig. 2. TG and DTG curves of PMMA samples: a) after heating in $180^{\circ} \mathrm{C}$; b) after heating in $210^{\circ} \mathrm{C}$; after heating in $240^{\circ} \mathrm{C}$.

According to the DTG curves the decomposition of all PMMA and PS samples takes place in a single step. The range of initial decomposition temperatures for PMMA granules is $182.5-281^{\circ} \mathrm{C}$. In comparison to the sample heated in $90^{\circ} \mathrm{C}$ for $120 \mathrm{~min}$ it can be observed that generally the temperature increases the thermal stability of all samples. The only exception are samples heated in $240^{\circ} \mathrm{C}$ for 40 and $60 \mathrm{~min}$, where thermal degradation occurred. In the case of PMMA for 180 and $210^{\circ} \mathrm{C}$, the values of ITD improved slightly towards longer heating times of material. This indicates the probable curing of the sample. The results for polymer heated in $240^{\circ} \mathrm{C}$ were less favourable, which points to a timing degradation phenomenon. Comparing the same heating time but different temperatures, one can say that with a temperature 
increase, in most cases, thermal stability decreases, which also indicates thermal decomposition. The maximum decomposition temperatures for all analysed PMMA granules remain comparable and are included in the range: $332 \div 34^{\circ} \mathrm{C}$, while the values of maximum decomposition rate of PMMA samples are of 17.0 to $26.1 \% / \mathrm{min}$.
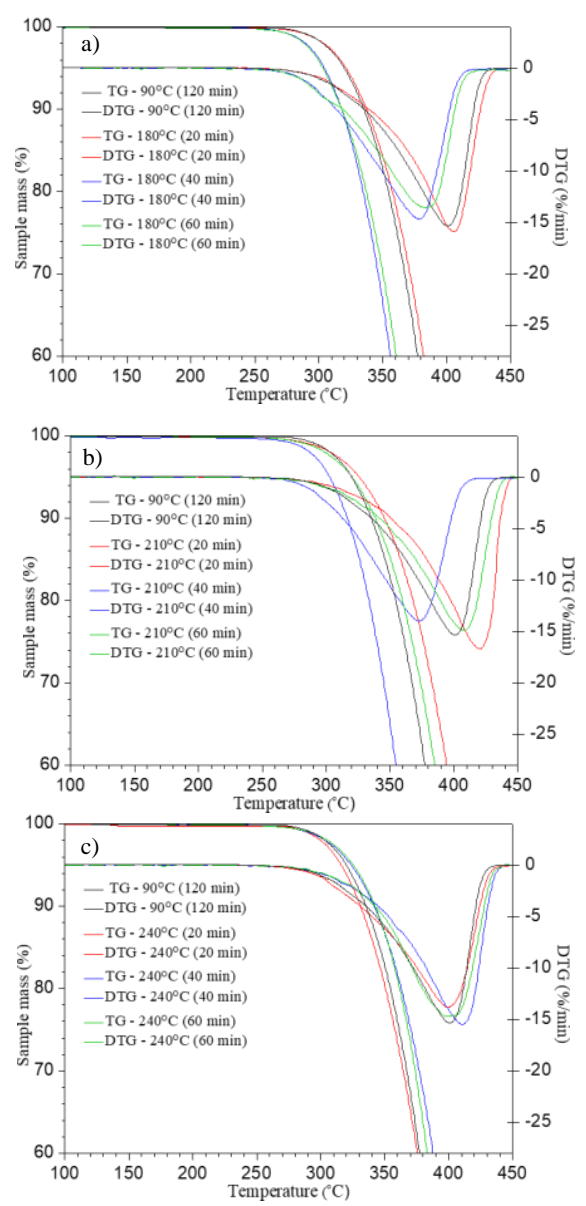

Fig. 3. TG and DTG curves of PS samples: a) after heating in $180^{\circ} \mathrm{C}$; b) after heating in $210^{\circ} \mathrm{C}$; after heating in $240^{\circ} \mathrm{C}$.

For PS granules the range of initial decomposition temperatures is visible from 278 to $305^{\circ} \mathrm{C}$. In comparison to the sample heated in $90^{\circ} \mathrm{C}$ for $120 \mathrm{~min}$ only the sample heated in $180{ }^{\circ} \mathrm{C}$ for $20 \mathrm{~min}$ shows slightly better thermal properties. The numerical data of ITD for PS (180 and $210^{\circ} \mathrm{C}$ ) showed reverse tendency compared with PMMA samples. Along with an increase in heating time the timing degradation occurs. Regarding samples heating in $240^{\circ} \mathrm{C}$, a slight increase in ITD values can be observed, but in comparison to PS heated in $180^{\circ} \mathrm{C}$ these results are worse. In this case, thermally degradation of polymer is observed. The values of maximum decomposition temperature for PS granules are diversified and the range of this parameter is from 378.5 to $420.5^{\circ} \mathrm{C}$, while the numerical data of sample maximum decomposition rate were in the range: $13.6 \div 16.7 \% / \mathrm{min}$.
Table 3. Data read from TG and DTG curves

\begin{tabular}{|c|c|c|c|c|c|c|}
\hline \multirow{2}{*}{ Samples } & \multicolumn{2}{|c|}{ IDT $\left[{ }^{\circ} \mathrm{C}\right]$} & \multicolumn{2}{c|}{ Max DTG [ $\left.{ }^{\circ} \mathrm{C}\right]$} & \multicolumn{2}{c|}{ DTG [\%/min] } \\
\cline { 2 - 7 } & PMMA & PS & PMMA & PS & PMMA & PS \\
\hline $\begin{array}{c}90^{\circ} \mathrm{C}- \\
120 \mathrm{~min}\end{array}$ & 240.5 & 301 & 339 & 400.5 & 19.5 & 15.3 \\
\hline $\begin{array}{c}80^{\circ} \mathrm{C}-20 \\
\text { min }\end{array}$ & 268 & 305 & 337.5 & 400.5 & 25.8 & 15.9 \\
\hline $\begin{array}{c}180^{\circ} \mathrm{C}- \\
40 \mathrm{~min}\end{array}$ & 280 & 282.5 & 338.5 & 378.5 & 18.0 & 14.7 \\
\hline $\begin{array}{c}180^{\circ} \mathrm{C}- \\
60 \mathrm{~min}\end{array}$ & 281 & 278 & 334 & 383 & 19.4 & 13.6 \\
\hline $\begin{array}{c}210^{\circ} \mathrm{C}- \\
20 \mathrm{~min}\end{array}$ & 264.5 & 293.5 & 335.5 & 420.5 & 23.1 & 16.7 \\
\hline $\begin{array}{c}210^{\circ} \mathrm{C}- \\
40 \mathrm{~min}\end{array}$ & 269.2 & 291 & 337 & 412.5 & 24.0 & 15.2 \\
\hline $\begin{array}{c}210^{\circ} \mathrm{C}- \\
60 \mathrm{~min}\end{array}$ & 277.5 & 289.5 & 336.5 & 408.1 & 26.1 & 14.9 \\
\hline $\begin{array}{c}240^{\circ} \mathrm{C}- \\
20 \mathrm{~min}\end{array}$ & 278 & 289 & 341 & 399.5 & 21.6 & 13.8 \\
\hline $\begin{array}{c}240^{\circ} \mathrm{C}- \\
40 \mathrm{~min}\end{array}$ & 203 & 295.7 & 332 & 410.7 & 17.2 & 15.5 \\
\hline $\begin{array}{c}240^{\circ} \mathrm{C}- \\
60 \mathrm{~min}\end{array}$ & 182.5 & 295.8 & 335.5 & 398.3 & 17.0 & 14.7 \\
\hline
\end{tabular}

Based on TG/DTG data obtained for PMMA it can be observed that for 180 and $210^{\circ} \mathrm{C}$ with a time increase the IDT values also increase. It means that samples aren't polymerized properly. It should be also noted that in a temperature of $240^{\circ} \mathrm{C}$ a drop in thermal properties is observed. Even if the degradation kinetics goes slower we should see that it is because we moved significantly to lower IDT values. The obtained results are confirmed by double bond conversion calculations. If it comes to the results obtained for PS we can conclude that degradation with time and temperature is observed, but by looking at double bond conversion the reverse tendency is observed. This can probably be explained by post-curing. With a time increase more double bonds are reacted, but because of the conversion low value the sample starts to lose mass at lower temperatures. Before starting the extrusion process, all tested samples should be pre-cured (it is a separate procedure from heating at $90^{\circ} \mathrm{C}$, which aim is to get rid of surface adsorbed water). Based on obtained data, it can be said that the temperature $210^{\circ} \mathrm{C}$ will be most proper for obtaining polymer optical fibers but the time in which the process takes place needs more studies.

\section{References}

[1] O. Ziemann, J. Krauser, P.E. Zamzow, W. Daum, POF Polymer Optical Fibersfor Data Communication (Berlin: Springer 2008).

[2] P. Stajanca et al., Opt. Fiber Technol. 41, 227 (2018).

[3] K. Peters, Smart Mater. Struct. 20, 013002 (2011).

[4] J. Zubia, J. Arrue, Opt. Fiber Technol. 7,101 (2001).

[5] M. Beckers, T. Schlüter, T. Gries, G. Seide, C.-A. Bunge, Polymer Opt. Fibres 187-199 (2017).

[6] M. Niedźwiedź , M. Gil, M. Gargol , W. Podkościelny, P. Mergo, Phot. Lett. Poland 11, 7 (2019). 